\title{
Corrigendum: Stargazin attenuates intracellular polyamine block of calcium-permeable AMPA receptors
}

David Soto, Ian D Coombs, Leah Kelly, Mark Farrant \& Stuart G Cull-Candy

Nat. Neurosci. 10, 1260-1267 (2007); published online 16 September 2007; corrected after print 23 October 2007

In the version of this article initially published, the filled and open symbols were switched in Figure $3 \mathrm{~b}$. A minus sign was also introduced into the text describing the figure. The figure has been corrected, and the sentence in the text beneath the figure should read: "By plotting conductance against voltage ${ }^{35}$, it can be seen that stargazin induced a $+33 \mathrm{mV}$ shift in the voltage for half-maximal block by spermine (Fig. $3 \mathbf{b}$ ).” The error has been corrected in the HTML and PDF versions of the article.

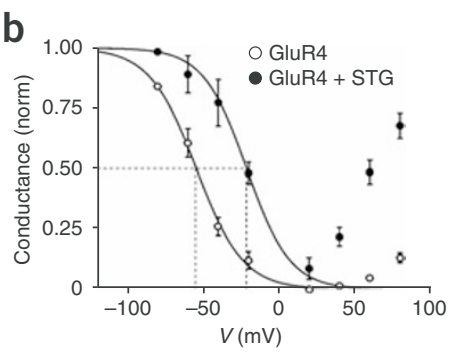

Figure 3 Effect of stargazin on polyamine block and deactivation of GluR4 AMPARs. (b) Plot of normalized conductance $(G)$ against voltage $\left(V_{m}\right)$ for GluR4 receptors with and without stargazin (data from Fig. 1b). Unbroken lines are fits (at negative voltages) to a Boltzmann function:

$$
G=G_{\max }\left(\frac{1}{1+\exp \left(\left(V_{m}-V_{1 / 2}\right) / k\right)}\right)
$$

where $G_{\max }$ is the maximal glutamate-activated conductance at hyperpolarized voltages, $V_{1 / 2}$ is the voltage at which spermine block is half-maximal (broken lines) and $k$ is a slope factor describing the membrane potential shift necessary to cause an e-fold change in conductance. The slopes of the fits were not different ( $k=15.5 \mathrm{mV}$ for GluR4 and $14.4 \mathrm{mV}$ for GluR4 plus stargazin), but $V_{1 / 2}$ shifted from -54.4 to $-21.2 \mathrm{mV}$. Similar results were obtained with GluR1.

\section{Corrigendum: The ins and outs of fMRI signals}

Nikos K Logothetis

Nat. Neurosci. 10, 1230-1232 (2007); published online 25 September 2007; corrected after print 23 October 2007

In the version of this article initially published online, the labeling on Figure 1c was incorrect. The error has been corrected in the HTML and PDF versions of the article.

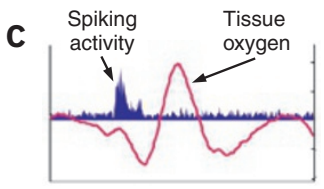

Figure 1 Activity in the visual cortex. (c,d) The experiments of Viswanathan and Freeman ${ }^{6}$ show that changes in oxygen concentration are also similar for low and high temporal frequencies, but spiking activity is only evident after low-frequency $(4 \mathrm{~Hz})$ stimuli (c) and is entirely absent for the gratings drifting at high frequencies $(30 \mathrm{~Hz})(\mathbf{d})$.

\section{Erratum: Stringing the fiddle: the inner ear's two-part invention}

\section{David P Corey}

Nat. Neurosci. 10, 1232-1233 (2007); published online 25 September 2007; corrected after print 23 October 2007

In the version of this article initially published, the legends for Figure $1 \mathrm{~d}$ and $\mathrm{f}$ were switched, and citations to these panels in the text were incorrect. In addition, references to specific animal models in ref. 10 were inaccurate. The errors have been corrected in the HTML and PDF versions of the article.

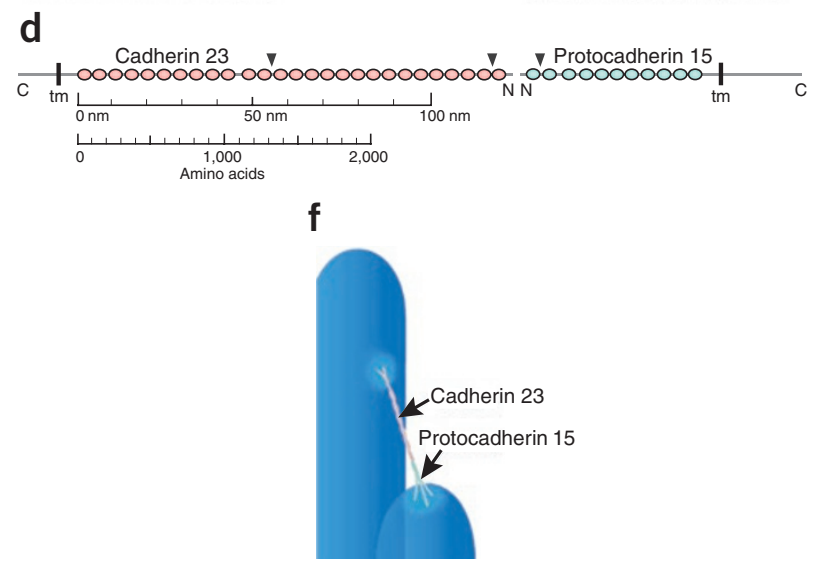

Figure 1 Structure of hair bundle stereocilia and tip links. (d) Domain structure and approximate length of cadherin 23 and protocadherin 15. $\mathrm{N}$ and $\mathrm{C}$ terminal transmembrane domains are indicated as $\mathrm{tm}$. Ovals represent cadherin ectodomains. Epitopes used for immunogold electron microscopy are indicated by arrowheads, and the antibody-binding positions on the tip links matched the spacing of epitopes on the cadherins. (f) Proposed molecular composition of a tip link. A parallel homodimer of cadherin 23 joins a parallel homodimer of protocadherin 15 , binding at their $\mathrm{N}$ termini (reproduced from ref. 1 by permission of Macmillan Publishers Ltd., copyright 2007). 